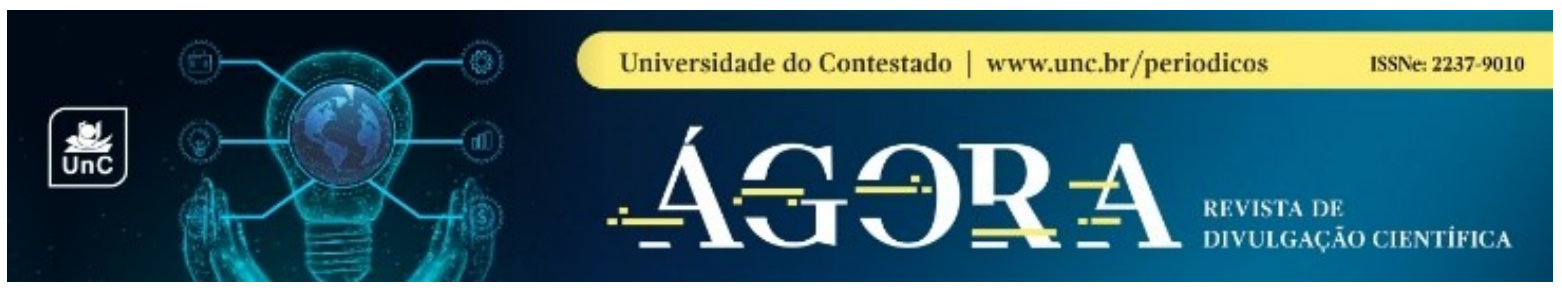

\title{
UTILIZAÇÃO DE MÉTODOS QUANTITATIVOS EM ESTUDOS DE TRANSPARÊNCIA EM PORTAIS ELETRÔNICOS GOVERNAMENTAIS ${ }^{1}$
}

\section{USE OF QUANTITATIVE METHODS IN STUDIES ABOUT ACCOUNTABILITY IN GOVERNMENTAL WEBSITES}

\author{
Kristinne Kelly Rosa Borges Vaz \\ Sandro Vieira Soares ${ }^{3}$ \\ Cristina Martins ${ }^{4}$ \\ Nélio Herzmann Junior ${ }^{5}$
}

\begin{abstract}
RESUMO
Esta pesquisa tem como objetivo delinear a utilização dos métodos quantitativos empregados em pesquisas sobre a transparência em portais eletrônicos governamentais. A análise partiu de um estudo bibliográfico com uma amostra de 22 artigos publicados nas bases de dados internacionais e nacionais: DOAJ, Redalyc, Scopus, Scielo e Spell. Os resultados evidenciaram o uso de técnica de estatística descritiva em $63,6 \%$ da amostra. Constatou-se também que $45,5 \%$ dos estudos estão utilizando a correlação de Pearson ou de Spearman. Foi observado que na condução dos estudos foi empregada a amostragem não probabilística por julgamento. Os softwares mais utilizados foram o Microsoft Excel e o Statistical Package for the Social Sciences (SPSS). Foi possível concluir que as pesquisas quantitativas na área de transparência em portais eletrônicos governamentais utilizam muito frequentemente de técnicas estatísticas simples, o que corrobora com a literatura. Foi possível concluir também que há margem para um detalhamento mais aprofundado dos procedimentos metodológicos adotados, o que contribuiria para o aumento do potencial de replicação dos estudos.
\end{abstract}

Palavras-chave: Transparência; Portais eletrônicos; Estatística; Métodos quantitativos.

\footnotetext{
1"O presente trabalho foi realizado com apoio da Coordenação de Aperfeiçoamento de Pessoal de Nível Superior - Brasil (CAPES) - Código de Financiamento 001." "O presente trabalho foi realizado com apoio do Instituto Ânima - IA."

${ }^{2}$ Mestranda em Administração - PPGA/UNISUL. Bolsista de mestrado da CAPES - PPGA/UNISUL. Servidora da Fundação Universidade Federal do Tocantins - UFT. Palhoça, Santa Catarina. Brasil. E-mail: kristinne@uft.edu.br ORCID: https://orcid.org/0000-0002-7007-7068

${ }^{3}$ Doutor em Controladoria e Contabilidade - FEA/USP. Professor da Universidade do Sul de Santa Catarina - UNISUL. Pesquisador do Instituto Ânima - IA. Palhoça, Santa Catarina. Brasil. E-mail: sandrovieirasoares@hotmail.com. ORCID: https://orcid.org/0000-0001-7076-4936

${ }^{4}$ Doutora em Administração - PPGADM/UFSC. Bolsista PNPD CAPES - PPGA/UNISUL. Professora do Centro Universitário Municipal de São José - USJ. Palhoça, Santa Catarina. Brasil. E-mail: crismartins2611@gmail.com. ORCID: https://orcid.org/0000-0001-8635-0981

5 Mestre em Administração - PPGA/UNISUL. Florianópolis, Santa Catarina. Brasil. E-mail: neliohir@hotmail.com
}

Ágora: R. Divulg. Cient., v. 27, p. 45-68, 2022 (ISSNe 2237-9010) 


\begin{abstract}
This research aims to outline the use of quantitative methods used in research on transparency in websites. The analysis was based on a bibliographic reseach with a sample of 22 papers published in international and national databases: DOAJ, Redalyc, Scopus, Scielo and Spell. The results showed the use of descriptive statistics technique in $63.6 \%$ of the sample. It was also found that $45.5 \%$ of the studies are using a Pearson or Spearman correlation. In conducting the studies, a non-probabilistic sampling by judgment was used. The most used software were Microsoft Excel and the Statistical Package for Social Sciences (SPSS). It was possible to conclude that quantitative research in the area of transparency in governing electronic portals very often uses simple statistical techniques, which corroborates the literature. It was also possible to conclude that there is oportunity for further detailing of the methodological procedures adopted, which would contribute to increasing the potential for replication of the studies.
\end{abstract}

Keywords: Accountability; Websites; Statistics; Quantitative methods.

\title{
1 INTRODUÇÃO
}

Existe um debate em todo o mundo acerca da "adoção de boas práticas de governança na gestão pública, a qual pressupõe administrar com responsabilidade, transparência e incentivo ao controle social na aplicação dos recursos públicos" (MORAIS; GUERRA, 2015, p. 2). Assim, a transparência pública passa a expandir para além das fronteiras da área legal/fiscal, e passa a abordar outras questões como desempenho, recursos humanos e controles internos da gestão pública, segundo Bairral, Silva e Alves (2015).

Neste sentido, Salgado e Aires (2017) apresentam que a temática da transparência pública tem se destacado nas publicações de artigos dos últimos anos, dentre outros pontos, tem-se analisado em diferentes realidades ou esferas públicas, a transparência e a participação democrática a partir de sítios eletrônicos. Na concepção de Nunes et al. (2013) a sociedade está entrando num novo estágio de entendimento que é o processo de fiscalização da administração pública, exigindo assim, mais transparência dos gestores em suas ações e utilização de recursos públicos.

As pesquisas no contexto da transparência em portais eletrônicos em diversas esferas (municipal, estadual e federal) apresentam a utilização de abordagens qualitativas, quantitativas ou mesmo mistas. Mas independentemente da abordagem 
adotada, segundo Espejo et al. (2013), a adequação metodológica é considerada o principal critério de avaliação utilizado pelos pareceristas de eventos e periódicos para avaliação de artigos.

Já para Almeida (2014), a falta de clareza no processo de amostragem e na técnica estatística empregada fica em segundo lugar, perdendo somente para questões de desatualização de revisão de literatura e/ou abrangência restrita. A rejeição dos artigos em periódicos de ciências contábeis, para Galvão, Silva e Mercês (2017), diz respeito a questões de pesquisa desatualizadas ou irrelevantes, ausência de explicação de forma detalhada da metodologia empregada na pesquisa e falta de generalização e discussão dos resultados.

A área de Administração, Contabilidade e Turismo vêm obtendo resultados importantes quando faz aplicação de técnicas estatísticas no aprimoramento e entendimento dos resultados. Segundo estudo de Silva, Wanderley e Santos (2011), ao analisar os artigos apresentados nos maiores congressos de Contabilidade, atentou-se que: mais de $50 \%$ dos artigos empregaram abordagem quantitativa, de forma que a incidência desta abordagem tem aumentado no decorrer dos anos.

$\mathrm{Na}$ Administração, amostras enviesadas ou pouco representativas, com limitações ou descrição deficiente das variáveis utilizadas e a equivocada forma de manipulação dos dados são características recorrentes em pareceres de recusa de artigos em revistas no Brasil, conforme aponta Ferreira e Falaster (2016). A principal seção que acarreta na rejeição direta (desk rejection) é a de método, segundo Falaster, Ferreira e Canela (2016).

Fiates, Serra e Martins (2014) e Prearo et al. (2011), ao pesquisar o contexto do uso de métodos quantitativos em pesquisas brasileiras na área de Administração, chegaram a três conclusões: i. os pesquisadores brasileiros têm proficiência somente em técnicas simples, como correlação e teste $t$, e inabilidade em técnicas mais requintadas; ii. os pesquisadores brasileiros mostram-se despreparados frente aos pesquisadores norte-americanos; iii. verifica-se que a maioria das pesquisas não confere as premissas das técnicas estatísticas empregadas.

Estudiosos como Lana et al. (2018) advertem que existem motivações para que algumas técnicas estatísticas tenham maior aplicabilidade que outras, e a inovação dos métodos tem que estar embasada em preceitos científicos. Assim, as pesquisas bibliográficas e bibliométricas podem ajudar pesquisadores para conhecer a área e 
direcionar suas escolhas metodológicas (LANA et al., 2018; SOARES; PICOLLI; CASAGRANDE, 2018).

Desta maneira, a questão de pesquisa que norteia esta investigação científica é: quais são os métodos quantitativos utilizados em pesquisas relacionadas à transparência em portais eletrônicos governamentais? Para responder a questão de pesquisa, tem-se como objetivo delinear a utilização dos métodos quantitativos empregados em pesquisas sobre a transparência em portais eletrônicos governamentais.

A constatação do uso equivocado de técnicas estatística em pesquisas nacionais, sugere a necessidade de discussão desse tema no meio acadêmico, visando difundir as boas práticas (BIDO; MANTOVANI; COHEN, 2017). Assim, existe espaço para o aperfeiçoamento das pesquisas quantitativas, no aspecto de validade e confiabilidade das análises (SOARES, T.; SOARES, J.; SOARES, S., 2019).

Quanto à utilização do método, é importante a citação de referências estatísticas, pois sinaliza adequação da aplicação da técnica, além de possibilitar o alicerce de outros trabalhos (SMANIA; SOARES; LIMA, 2019). Os resultados do estudo de Borges et al. (2020) mostram que muitos artigos não demonstram de forma precisa os procedimentos metodológicos aplicados, dificultando a análise mais acurada das técnicas estatísticas adotadas. Estudos podem contribuir para a disseminação dos modelos estatísticos de análise utilizados na área, e ainda estimular a adesão de algumas técnicas de análise ainda pouco exploradas. Para Damázio, Soares e Lima (2020), algumas pesquisas não apresentam de forma detalhada, os procedimentos aplicados, o que dificulta uma análise mais acurada das técnicas estatísticas empregadas em consonância a Borges et al. (2020).

Com base em Castro (2006) acredita-se que a presente pesquisa se apresenta relevante e viável, pois está ligada a uma questão que vem requerendo importância e atenção continuada na literatura especializada. A constância no tocante ao tema da presente pesquisa é constatada pelas pesquisas de Dallabona, Nascimento e Hein (2010), Gouvêa, Prearo e Romeiro (2010), Gouvêa, Prearo e Romeiro (2011), Hosser, Cruz e Quintana (2018), Prearo, Gouvêa e Romeiro (2011b), Prearo, Gouvêa e Romeiro (2012), Prearo, Gouvêa, Romeiro (2011a). Três estudos foram fortemente influenciadores da presente pesquisa: Agostineto et al. (2020), Borges et al. (2020) e Damázio, Soares e Lima (2020). 
A composição deste artigo é detalhada em cinco seções: na seção 1 apresentase a contextualização da aplicação de métodos quantitativos nas pesquisas de transparência de portais eletrônicos governamentais, na seção 2 apresenta-se a revisão de literatura; na seção 3 apresenta-se os procedimentos metodológicos; na seção 4 faz-se a análise dos resultados e discussão e na seção 5 apresenta-se a conclusão.

\section{REVISÃO DA LITERATURA}

A literatura brasileira sobre o uso de métodos quantitativos nas áreas de Administração, Contabilidade e Turismo ainda é pequena mas já engloba uma série de estudos com temas como adequação do uso de técnicas, como Prearo, Gouvêa e Monari (2009), diversidade de técnicas usadas em eventos científicos e programas de pós-graduação, como Silva, Wanderley e Santos (2010), e diversidade de técnicas usadas por tema de pesquisa, como Garcia, Soares e Lima (2019). A seguir apresenta-se a literatura revisada para este artigo em ordem cronológica.

Prearo, Gouvêa e Monari (2009) ao analisarem dissertações e teses de instituições de ensino superior, no período de 1997 a 2006, na área de Marketing, voltadas para o comportamento do consumidor, com o intuito de avaliar a adequação da aplicação das técnicas estatísticas multivariadas de regressão logística, constatou positiva a coerência e a ligação da técnica com a questão de pesquisa. Apesar disso, observaram uma fragilidade no ambiente operacional, quanto ao uso e atendimento as premissas subjacentes à técnica, que somente $50 \%$ das aplicações de análise de regressão logística atenderam plenamente as suas premissas. Deste modo, sugerem maior observância dos preceitos teóricos de aplicação da técnica de análise de regressão logística.

Gouvêa, Prearo e Romeiro (2010), ao avaliarem a aplicação das técnicas de regressão e análise conjunta a partir de dissertações e teses, em instituições de ensino superior na área de Marketing, abrangendo comportamento do consumidor no período de 1997 a 2006, identificaram que a aplicação das duas técnicas convergiram entre a categoria-objetivo de aplicação, com a categoria do problema de pesquisa. Mas somente a aplicação da técnica de análise de regressão apresentou uso adequado quanto ao atendimento de suas premissas. 
Silva, Wanderley e Santos (2010) analisaram o emprego da abordagem quantitativa, considerando 299 artigos, veiculados no congresso da ANPCONT, no congresso USP de Controladoria e Contabilidade e no EnANPAD, no período de 2007 a 2009. Os autores concluíram que a aplicação da abordagem quantitativa teve um crescimento de 46\% em 2007, para 62\% em 2009, o que representou 162 trabalhos da amostra. Os autores constataram também que 50\% dos artigos utilizaram as técnicas estatísticas, observando a aplicação de 11 (onze) técnicas, entre as quais se destacaram a inferência estatística, a análise de regressão e a estatística descritiva. Também verificaram que as universidades do sudeste do Brasil, como USP e FUCAPE, são responsáveis por impactar na disseminação de artigos voltados para as abordagens quantitativas. Assim, sugerem a disseminação dos modelos estatísticos, com intuito de incentivar pesquisadores a trabalhar com técnicas pouco exploradas.

Prearo, Gouvêa e Romeiro (2011a) abordaram a adequação de uso das técnicas estatísticas de regressão e correlação canônica, nas dissertações e teses de instituições ensino superior, voltadas para Marketing, na temática do comportamento do consumidor, entre 1997-2006. Suas conclusões foram positivas quanto à adequação das duas técnicas ao problema de pesquisa. Todavia, os autores perceberam quanto à técnica análise de regressão houve um número baixo de premissas atendidas em $66,7 \%$, com exceção do tamanho da amostra. Neste caso nenhuma das premissas mostrou mais que $30 \%$ de atendimento.

Prearo, Gouvêa e Romeiro (2011b) realizaram um estudo com foco na técnica de modelagem de equações estruturais, na área de Marketing, em programas de pósgraduação de duas universidades públicas - Faculdade de Economia, Administração e Contabilidade da Universidade de São Paulo; e a Escola de Administração Federal do Rio Grande do Sul. Inicialmente os autores perceberam que as aplicações da técnica de modelagem de equações estruturais estão adequadas entre a categoriaobjetivo de aplicação desta técnica com a categoria do problema de pesquisa. Por outro lado $84,2 \%$, das aplicações da técnica atenderam parcialmente as suas premissas, e no tocante a qualidade somente $15,8 \%$ apresentaram uso adequado da técnica quanto o atendimento de todas suas premissas.

Gouvêa, Prearo e Romeiro (2011) mapearam a aplicabilidade da análise multivariada de variância, em dissertações e teses, de algumas instituições de ensino 
superior, voltadas para área de Marketing, no intervalo de 1997 a 2006 . Eles constataram convergência em $100 \%$ dos casos entre a categoria-objetivo de aplicação desta técnica com a categoria do problema da pesquisa. Mas salientaram que no tocante a qualidade de aplicação desta técnica não se evidenciou o cumprimento de todas as suas premissas revelando que nenhuma das aplicações de análise multivariada de variância foi totalmente adequada. Desta maneira, os autores relataram a importância da observância dos preceitos teóricos subjacentes à técnica de análise multivariada de variância.

Dallabona, Rodrigues e Hein (2011) ao abordarem métodos quantitativos mais recorrentes nos estudos científicos publicados nos anais de congressos 3Es, EnADI, EnGPR, EnEPQ e EnANPAD, referentes ao ano de 2009, observaram a predominância de análise de frequência, análise de conteúdo, médias, mediana, moda, desvio padrão, percentuais, redes, teste estandardizado, assimetria e curtose. Por outro lado, verificaram que 71 trabalhos utilizaram análises multivariada de dados como: Análise fatorial, Agrupamentos hierárquicos, ANOVA, Análise de Clusters, Teste exato de Fischer, Análise dos conglomerados, Análise discriminante, Análise dos componentes principais, Coeficiente de Correlação de Pearson, Teste KaiserMeyer-Olkin; Alfa de Cronbach e Análise de correspondência. Outro apontamento feito pelos autores é que 63 estudos apresentaram a aplicação do método estatístico de regressão e correlação, predominando o teste de Durbin-Watson, teste Kruskal-Wallis, a Correlação entre Variáveis, Regressão simples, Regressão logística, Correlação canônica, Teste de multicolinearidade, Testes Kolmogorov-Smirnov e Teste QuiQuadrado. Por fim, identificaram ocorrência e relevância dos métodos estatísticos cada vez mais ampliados nos estudos científicos, e publicados em anais e periódicos.

Prearo, Gouvêia e Romeiro (2012) ao analisarem a adequação do uso de técnicas estatísticas de dependência (análise de regressão, análise discriminante, análise de regressão logística, correlação canônica, análise multivariada de variância, análise conjunta e modelagem de equações estruturais) identificaram que a análise de regressão se destaca como a técnica de dependência mais empregada nos trabalhos, seguindo uma tendência crescente de utilização da modelagem de equações estruturais.

Bido, Mantovani e Cohen (2018) avaliaram o uso da análise fatorial exploratória (AFE), a partir de 97 artigos (61 internacionais e 36 nacionais), com um total de 140 
aplicações da análise fatorial (AF), voltados para área de Produção e Operações, no período 2010 a 2015. Os autores concluíram que nos artigos internacionais foi predominante o uso das técnicas confirmatórias e a aplicação da AFE visando avaliar o common method bias. No caso dos artigos nacionais, os autores observaram a utilização da técnica com funções mais tradicionais, como a avaliação da unidimensionalidade ou ainda a geração de escores, para uso em outras técnicas. Os autores ainda constataram que em quatro artigos nacionais utilizou-se a AF Exploratória, sendo que a aplicação adequada seria a AF Confirmatória, com isto causando destruição da teoria. No mais, os autores arremataram que as pesquisas nacionais estão usando inadequadamente a técnica, o que indica necessidade de uma discussão no meio acadêmico, para difundir as boas práticas.

Hosser, Cruz e Quintana (2018) analisaram os métodos quantitativos utilizados nos trabalhos apresentados em nove edições do congresso da ANPCONT, com uma amostra de 637 artigos, no período de 2007 a 2015, distribuídos em quatro linhas de pesquisa: Controladoria e Contabilidade Gerencial (CCG); Contabilidade para Usuários Externos (CUE); Educação e Pesquisa em Contabilidade (EPC) e Mercados Financeiro, de Créditos e de Capitais (MFCC). Os resultados evidenciaram que o teste $t$ student foi o mais aplicado no (CCG), seguido do uso de técnica de correlação (CUE e MFCC). A técnica do Qui-Quadrado se sobressaiu em EPC. Os autores averiguaram que das 198 técnicas estatísticas encontradas, 30 são constituídas de principais, 14 autônomas, 148 acessórias e 6 classificadas em outros grupos. Desta maneira, observaram que nos congressos da ANPCONT ocorreu uma diversidade no emprego das técnicas estatísticas, demonstrando que os pesquisadores de contabilidade vêm explorando, e ampliando novas técnicas, observando que prevalece a ótica quantitativa nesses congressos.

Soares T., Soares J. e Soares, S. (2019) mapearam as publicações nacionais na área de turismo, com base em nos periódicos da temática com Qualis B ou superior, através de uma revisão sistemática da literatura. Os autores apontaram que pouco mais de $15 \%$ dos estudos que utilizaram questionários não explicitaram o uso da análise fatorial no contexto de identificar sua validação. Outro achado é que nenhum estudo mencionou a utilização da teoria de resposta ao item. Ao tratar de confiabilidade, evidenciaram que menos de $10 \%$ dos estudos que envolveram questionário informaram ter procedido a análise de consistência interna, e pouco 
acima de $2 \%$, utilizaram análise de multicolinearidade dos dados, e menos de $2 \%$ analisou a normalidade, linearidade e homoscedasticidade dos dados. Assim sendo, os autores concluíram que o campo da pesquisa em turismo precisa se preocupar em gerar dados primários válidos e confiáveis.

Garcia, Soares e Lima (2019) analisaram a aplicação de métodos quantitativos empregados em estudos referentes a Servqual e suas variações na avaliação de sistemas de informações. Os estudiosos constataram que as técnicas estatísticas de mensuração com a escala do tipo Likert ocorreram em $100 \%$ dos artigos pesquisados, com uma variação de 5 a 9 pontos. O coeficiente de Alfa de Cronbach foi o mais utilizado para atestar a confiabilidade de questionários. Também constataram a repetição da aplicação de algumas técnicas que envolviam teste de hipóteses, paramétricos e não paramétricos, assim como análise fatorial, confirmatória e exploratória. Desta feita, constataram que a análise de agrupamento e a modelagem de equações estruturais foram utilizadas em menor frequência. Assim, os autores apresentaram um cenário de quais métodos quantitativos estão sendo utilizados nas aplicações do modelo Servqual.

Vários dos estudos acima foram mapeados pelas pesquisas de Agostineto et al. (2020), Borges et al. (2020) e Damázio, Soares e Lima (2020). Borges et al. (2020) analisaram o emprego de métodos quantitativos nas pesquisas em Marketing de relacionamento com egressos, a partir de um portfólio de 20 artigos publicados até 2018. Os autores constataram que a expressiva maioria dos artigos fez a utilização das técnicas estatísticas de modelagem de equações estruturais, análise fatorial confirmatória, e estatística descritiva. Entre os testes de consistência interna e de confiabilidade foi utilizado principalmente o coeficiente Alfa de Cronbach. Já entre as escalas de mensuração, as mais utilizadas são a escala Likert de 5 e 11 pontos. Desta maneira, os autores colaboraram para alargar o domínio quanto aos métodos quantitativos, visando auxiliar futuras pesquisas na área.

Como pode ser visto nos relatos acima, há uma multiplicidade de técnicas que vem sendo adotadas em diversas áreas da administração. Nem todas são empregadas adequadamente. E muitas vezes é difícil identificar detalhadamente o processo de escolhas metodológicas realizadas pelos pesquisadores e, portanto, é difícil conseguir replicar as pesquisas. 


\section{PROCEDIMENTOS METODOLÓGICOS}

Esta pesquisa é tipificada como bibliográfica. O levantamento para o estudo ocorreu durante o mês de julho de 2020 sendo também o corte temporal final de coleta de dados. Entretanto, optou-se por não definir corte inicial temporal com o intuito de ter a maior abrangência possível. Dando prosseguimento, partiu-se para definição das bases de dados a serem consultadas. Considerando a importância na difusão dos estudos científicos, as seguintes bases de dados internacionais e nacionais foram selecionadas: DOAJ, Redalyc, Scopus, Scielo e Spell.

Em seguida, dirigiu-se a cada base de dados aplicando as seguintes palavraschave no campo de busca: 'transparência' e 'portais eletrônicos', 'transparência' e 'website', 'transparência' e 'digital', 'índice' e 'transparência' e 'indicadores' e 'transparência'. A utilização dessas palavras-chave foi determinada pela leitura inicial de alguns artigos sobre o tema que já utilizavam algumas destas palavras-chave e suas variações, como no caso de "portais eletrônicos" e "website". Tal procedimento resultou em um total de 60 artigos.

$\mathrm{Na}$ sequência, iniciou-se um processo de refinamento realizando a leitura dos títulos e resumos dos artigos. Iniciaram nesse refinamento 60 artigos, os quais após análise preliminar eliminou-se 9 (nove) artigos em duplicidade. Dos 51 (cinquenta e um) artigos restantes, após análise preliminar dos resumos, ressalta-se que 29 (vinte e nove) possuíam abordagem qualitativa, e por isto, não foram considerados alinhados ao objetivo da presente pesquisa, que é a análise do emprego de métodos quantitativos, de modo que restaram na amostra 22 (vinte e dois) artigos que utilizaram a abordagem quantitativa. Em síntese, os critérios foram: 1. Eliminar os artigos duplicados e 2. Eliminar os artigos de abordagem qualitativa.

Diante do exposto, a Tabela 1 detalha os procedimentos de refinamento utilizados nas bases de dados mencionadas.

Tabela 1 - Detalhamento da pesquisa

\begin{tabular}{c|c|c}
\hline Base & Número de resultados & Artigos selecionados \\
\hline DOAJ & 19 & 12 \\
\hline Redalyc & 7 & 0 \\
\hline Scopus & 8 & 1 \\
\hline Scielo & 12 & 5 \\
\hline Spell & 14 & 4 \\
\hline Total & $\mathbf{6 0}$ & $\mathbf{2 2}$ \\
\hline Total excluídos os qualitativos e duplicados & $\mathbf{3 8}$ \\
\hline
\end{tabular}

Fonte: Elaborado pelos autores (2020).

Ágora: R. Divulg. Cient., v. 27, p. 45-68, 2022 (ISSNe 2237-9010) 
Uma vez realizado o refinamento, a amostra da pesquisa foi composta por 22 artigos que foram analisados a partir de leitura integral e especialmente atenta do resumo, metodologia e resultados. O Quadro 1 apresenta os títulos, autores e ano dos artigos.

Quadro 1 - Amostra de artigos final

\begin{tabular}{|c|c|c|}
\hline TÍTULOS DOS ARTIGOS & AUTORES & ANO \\
\hline $\begin{array}{l}\text { Prosopografia a partir da web: avaliando e mensurando as fontes } \\
\text { para o estudo das elites parlamentares brasileiras na internet }\end{array}$ & Braga; Nicolás & 2008 \\
\hline $\begin{array}{l}\text { Transparência da gestão fiscal: um estudo a partir dos portais } \\
\text { eletrônicos dos maiores municípios do estado do Rio de Janeiro }\end{array}$ & Cruz; Silva; Santos & 2009 \\
\hline $\begin{array}{l}\text { Transparência fiscal eletrônica: uma análise dos níveis de } \\
\text { transparência apresentados nos sites dos poderes e órgãos dos } \\
\text { Estados e Distrito Federal do Brasil }\end{array}$ & $\begin{array}{l}\text { Santana; Libonati; } \\
\text { Vasconcelos; } \\
\text { Slomski }\end{array}$ & 2009 \\
\hline $\begin{array}{l}\text { Práticas de accountability: uma análise do índice de transparência } \\
\text { nos municípios mais populosos de Santa Catarina }\end{array}$ & $\begin{array}{l}\text { Keunecke; Teles; } \\
\text { Flach }\end{array}$ & 2011 \\
\hline $\begin{array}{l}\text { Transparência da gestão pública municipal: um estudo a partir dos } \\
\text { portais eletrônicos dos maiores municípios brasileiros }\end{array}$ & $\begin{array}{l}\text { Cruz; Ferreira; Silva; } \\
\text { Macedo }\end{array}$ & 2012 \\
\hline $\begin{array}{l}\text { Análise dos instrumentos de transparência contidos na lei de } \\
\text { responsabilidade fiscal nos municípios da região Sul }\end{array}$ & $\begin{array}{l}\text { Nunes; Santos; } \\
\text { Farias; Soares; } \\
\quad \text { Lunkes }\end{array}$ & 2013 \\
\hline $\begin{array}{l}\text { Índice de transparência municipal: um estudo nos municípios mais } \\
\text { populosos do Rio Grande do Norte }\end{array}$ & $\begin{array}{l}\text { Souza; Barros; } \\
\text { Araújo; Silva }\end{array}$ & 2013 \\
\hline $\begin{array}{l}\text { Comunicação pública, transparência e políticas públicas: avaliação } \\
\text { de informações em portais brasileiros de governo }\end{array}$ & Rothberg; Liberato; & 2013 \\
\hline Transparência na gestão fiscal nos municípios do Estado do Ceará & $\begin{array}{l}\text { Rodr } \\
\text { Salg }\end{array}$ & 2015 \\
\hline $\begin{array}{l}\text { Disponibilização de informações à sociedade em meios eletrônicos: } \\
\text { um estudo nas prefeituras dos maiores municípios brasileiros }\end{array}$ & $\begin{array}{l}\text { Raupp; Abreu; } \\
\text { Abreu }\end{array}$ & 2015 \\
\hline $\begin{array}{l}\begin{array}{l}\text { Transparência digital na gestão pública: uma análise de } \\
\text { conglomerados nos municípios cearenses }\end{array} \\
\end{array}$ & $\begin{array}{l}\text { Diniz; Machado; } \\
\text { Matos } \\
\end{array}$ & 2016 \\
\hline $\begin{array}{l}\text { Transparência no poder legislativo municipal: uma análise dos portais } \\
\text { eletrônicos das câmaras de vereadores das capitais brasileiras }\end{array}$ & $\begin{array}{l}\text { Campagnoni; } \\
\text { Carvalho; Lyrio; } \\
\text { Lunkes; Rosa }\end{array}$ & 2016 \\
\hline $\begin{array}{l}\text { A transparência ativa nos municípios de Santa Catarina: avaliação do } \\
\text { índice de atendimento a lei de acesso a informação e suas } \\
\text { determinantes }\end{array}$ & $\begin{array}{l}\text { Comin; Ramos; } \\
\text { Zucchi; Favretto; } \\
\text { Fachi }\end{array}$ & 2016 \\
\hline $\begin{array}{l}\text { Índice de transparência dos governos locais: determinantes da } \\
\text { classificação dos municípios }\end{array}$ & Araújo; Romero & 2016 \\
\hline $\begin{array}{l}\text { Transparência pública mediada por computadores: como estão os } \\
\text { ministérios de Moçambique à luz da legislação? }\end{array}$ & $\begin{array}{c}\text { Cole; Lyrio; Lunkes; } \\
\text { Lima }\end{array}$ & 2017 \\
\hline $\begin{array}{l}\text { Governo eletrônico no Rio Grande do Norte: uma avaliação de } \\
\text { prefeituras municipais a partir de lei de acesso à informação }\end{array}$ & Salgado; Aires & 2017 \\
\hline $\begin{array}{l}\text { A influência dos índices socioeconômicos e contábeis no nível de } \\
\text { transparência eletrônica dos estados brasileiros sob a ótica da Teoria } \\
\text { da Escolha pública }\end{array}$ & $\begin{array}{l}\text { Fiirst; Baldissera; } \\
\text { Martins; Nascimento }\end{array}$ & 2018 \\
\hline $\begin{array}{l}\text { Da opacidade à transparência? Avaliando a lei de acesso à } \\
\text { informação no Brasil cinco anos depois }\end{array}$ & $\begin{array}{c}\text { Michener; } \\
\text { Contreras; Niskier }\end{array}$ & 2018 \\
\hline $\begin{array}{l}\text { Transparência e índices de gestão em entidades públicas como } \\
\text { ferramenta de controle e desempenho: uma comparação entre } \\
\text { indicadores municipais de Alagoas }\end{array}$ & Teixeira; Lamenha & 2019 \\
\hline $\begin{array}{l}\text { Um olhar sobre o governo aberto no nível subnacional: o índice } \\
\text { institucional do governo municipal aberto nas principais cidades do } \\
\text { Brasil }\end{array}$ & Dias; Garcia; Camilo & 2019 \\
\hline
\end{tabular}

Ágora: R. Divulg. Cient., v. 27, p. 45-68, 2022 (ISSNe 2237-9010) 


\begin{tabular}{|l|c|c|}
\hline $\begin{array}{l}\text { Proposta de índice bidimensional de transparência da informação } \\
\text { público-eletrônica como ferramenta para participação e controle } \\
\text { sociais }\end{array}$ & Melo; Fuchigami & 2019 \\
\hline $\begin{array}{l}\text { Transparência na gestão pública municipal evidenciada nos portais } \\
\text { eletrônicos dos municípios do conselho regional de desenvolvimento } \\
\text { (COREDE) das Missões/RS }\end{array}$ & Visentini; Santos & 2019 \\
\hline
\end{tabular}

Fonte: Elaborada pelos autores (2020).

Pode-se notar que o tema é composto exclusivamente por artigos desenvolvidos em parcerias haja vista que nenhum deles foi assinado por um único autor, embora isto tenha se mostrado como uma tendência em diversas áreas do conhecimento. O mais antigo data de 2008, o que pode ser considerado relativamente recente. Na próxima seção passa-se a apresentar os resultados e discussões da pesquisa.

\section{RESULTADOS E DISCUSSÃO}

A estrutura da administração pública brasileira é dividida por esferas de administração e poder: Federal, Estadual e Municipal. Nos resultados dos estudos sobre a temática, ficou demonstrada a ocorrência de análise de informações em portais tanto na esfera federal, estadual e municipal, englobando os órgãos dos poderes executivo, legislativo e judiciário, e em alguns casos agrupados por regiões e poderes. Foi encontrado, inclusive, um estudo de transparência de ministérios de Moçambique. Ficou demonstrado que $72,7 \%$ das pesquisas foram direcionadas à esfera municipal, inclusive ocorrendo um estudo referente a municípios espanhóis. Conforme Tabela 2, evidencia-se o quantitativo de estudos por esfera de governo, quais sejam: federal, estadual e municipal.

Tabela 2 - Número de estudos por esfera de governo

\begin{tabular}{c|c|c}
\hline Esferas de governo & Quantidade artigos & $\%$ \\
\hline Municipal - Município & 16 & 72,7 \\
\hline Federal - União & 2 & 9,1 \\
\hline Estadual - Estado & 4 & 18,2 \\
\hline Total geral & 22 & 100,0 \\
\hline
\end{tabular}

Fonte: elaborado pelos autores (2021).

É possível que a recorrência de estudos com municípios decorra de questões relacionadas a obtenção da amostra, ou seja, disponibilidade de dados, mas também que decorra de questões relacionadas a importância da questão de pesquisa, pois o 
município pode parecer, aos olhos de pesquisadores, uma esfera de governo mais próxima do cidadão, que é o principal potencial interessado em estudos sobre transparência do governo. Pesquisas de campo futuras podem esclarecer esse fenômeno.

A categorização dos métodos quantitativos aplicados nos estudos é detalhada na Tabela 3:

Tabela 3 - Frequência absoluta e relativa das técnicas estatísticas da amostra

\begin{tabular}{l|c|c}
\multicolumn{1}{c|}{ Descrição técnica estatística } & Frequência absoluta & Frequência Relativa \\
\hline Estatística Descritiva & 14 & 63,6 \\
\hline Correlação de Pearson & 6 & 27,3 \\
\hline Correlação de Spearman & 4 & 18,2 \\
\hline Análise Regressão Linear/Múltipla & 4 & 18,2 \\
\hline Análise de Conglomerados & 2 & 9,1 \\
\hline Metodologia Multicritério de Apoio a Decisão & 2 & 9,1 \\
\hline Análise de Regressão Logística & 1 & 4,5 \\
\hline Análise de Regressão Poisson & 1 & 4,5 \\
\hline Análise Correspondência Múltipla & 1 & 4,5 \\
\hline Teste de Normalidade & 1 & 4,5 \\
\hline Análise de Confiabilidade & 1 & 4,5 \\
\hline
\end{tabular}

Fonte: elaborada pelos autores (2020).

Identificou-se o emprego de técnicas estatísticas descritivas (moda, mínimo, média e desvio padrão) em 63,6\% dos artigos da amostra, o que vai ao encontro do estudo de Fiates, Serra e Martins (2014) que indicam o amplo uso de técnicas estatísticas mais simplificadas na área de administração.

Fiates, Serra e Martins (2014) indicam que o aprimoramento das competências em métodos quantitativos, traria aos pesquisadores uma melhora do nível de suas pesquisas, de forma a utilizar de métodos mais sofisticados e mais adequados. Quanto a medidas de coerência ou consistência interna e confiabilidade, somente um artigo da amostra procedeu à aplicação do coeficiente de Alfa de Cronbach. Para Cooper e Schindler (2016, p. 262) "A confiabilidade está relacionada à estimativa do grau em que uma mensuração é livre de erro aleatório ou instável." Quando autores não explicitam a confiabilidade da mensuração com medidas como o Alfa de Cronbach, por exemplo, resta ao leitor a dúvida se a pesquisa não é, de fato, confiável ou se é confiável, mas apenas não mostra evidências explícitas disto.

Constatou-se ainda a utilização em dois estudos a utilização da Metodologia Multicritério de Apoio à Decisão - Construtivista (ENSSLIN; MONTIBELLER-NETO; NORONHA, 2001), sendo que em um deles a metodologia foi adaptada, e chamada 
Utilização de métodos quantitativos em estudos de transparência em portais eletrônicos governamentais

de modelo multicritério de Nunes (2013). Outra observação constatada foi que 45,5\% dos estudos estão utilizando a correlação de Pearson ou de Spearman. O Quadro 2 apresenta as variáveis utilizadas na correlação de Pearson e Spearman existentes nos estudos.

\begin{tabular}{|c|c|c|}
\hline Variável & Variável & Correlação \\
\hline $\begin{array}{l}\text { Escala Brasil Transparente dos } \\
\text { municípios - índices EBT / CGU, IEGM } \\
\text { / IRB, IFGF / FIRJAN. }\end{array}$ & $\begin{array}{l}\text { FPM, Grau de Urbanização nos municípios de } \\
\text { Alagoas, PIB per capita, densidade demográfica }\end{array}$ & Pearson \\
\hline $\begin{array}{l}\text { Índice Institucional de Governo Aberto } \\
\text { Municipal - IIGAM-Brasil. }\end{array}$ & $\begin{array}{l}\text { Dados socioeconômicos (Índice de } \\
\text { Desenvolvimento Humano Municipal (IDH-M), a } \\
\text { taxa de analfabetismo, o Produto Interno Bruto - } \\
\text { PIB, Renda Per Capita Média, Expectativa de } \\
\text { anos de estudo, Estimativa da População, } \\
\text { Produto Interno Bruto per capita, Percentual de } \\
\text { inserção digital/uso da internet. }\end{array}$ & Pearson \\
\hline $\begin{array}{l}19 \text { indicadores constantes da Lei de } \\
\text { Acesso à Informação. }\end{array}$ & $\begin{array}{l}\text { Fatores socioeconômicos, como população } \\
\text { total, IDH, PIB e receita arrecadada }\end{array}$ & Pearson \\
\hline $\begin{array}{l}\text { Requisitos de tempestividade e de } \\
\text { padrão mínimo de qualidade das } \\
\text { informações divulgadas nos Portais da } \\
\text { Transparência dos Municípios que } \\
\text { compõem o Estado do Ceará. }\end{array}$ & $\begin{array}{l}\text { Área do Município; Distância da Capital; } \\
\text { População; Quantidade de salas de aula } \\
\text { utilizadas; Quantidade de professores; Renda } \\
\text { da população; Quantidade de empregos; } \\
\text { População fora da faixa da pobreza; Índice de } \\
\text { Desenvolvimento Municipal (IDM); Índice de } \\
\text { Desenvolvimento Humano (IDH); Produto } \\
\text { Interno Bruto (PIB); Receita tributária; e } \\
\text { Despesas Empenhadas. }\end{array}$ & Pearson \\
\hline $\begin{array}{l}\text { Índice de transparência fiscal } \\
\text { eletrônica (metodologia proposta por } \\
\text { Santana Júnior, 2008) }\end{array}$ & $\begin{array}{l}\text { Taxa de alfabetização, população total, PIB per } \\
\text { capita, receita arrecadada, índice de } \\
\text { desenvolvimento humano municipal (IDH-M), } \\
\text { índice de qualidade dos municípios (IQM). }\end{array}$ & $\begin{array}{l}\text { Pearson/ } \\
\text { Spearman }\end{array}$ \\
\hline $\begin{array}{l}\text { Índice de transparência, que é o índice } \\
\text { fornecido pela TI-Espanha. }\end{array}$ & $\begin{array}{l}\text { Fatores políticos (Participação Eleitoral, } \\
\text { ideologia política, a competição política e o } \\
\text { gênero) e variáveis de controle (População por } \\
\text { Tamanho, Desemprego, Investimento e Dívida). }\end{array}$ & $\begin{array}{l}\text { Pearson/ } \\
\text { Spearman }\end{array}$ \\
\hline $\begin{array}{l}\text { Variável representativa dos níveis de } \\
\text { transparência fiscal eletrônica do } \\
\text { Poder/Órgão, elaborado pela própria } \\
\text { pesquisa. }\end{array}$ & $\begin{array}{l}\text { Indicadores econômicos: Receita Total, } \\
\text { Despesa Total, Resultado Primário, } \\
\text { Receita Corrente Líquida, Ativo Real, Passivo } \\
\text { Real er Dívida Consolidada. } \\
\text { Indicadores Sociais: População Total, Número } \\
\text { de Municípios, População Urbana Alfabetizada, } \\
\text { Populaçãor Urbanar Alfabetizada } \\
\text { Funcionalmente, População Adulta com } 11 \text { Anos } \\
\text { ou mais de Estudo, Número de Moradores com } \\
\text { Renda Mensal Superior a } 10 \text { Salários Mínimos e } \\
\text { Moradores com Acesso à Internet. }\end{array}$ & Spearman \\
\hline $\begin{array}{l}\text { Índice de Transparência (metodologia } \\
\text { proposta por Biderman e Puttomatti, } \\
\text { 2011) }\end{array}$ & $\begin{array}{l}\text { Variáveis socioeconômicas dos municípios } \\
\text { (IDEB do } 5 \text { e } 9^{\circ} \text { ano; IDH). }\end{array}$ & Spe \\
\hline
\end{tabular}

Fonte: elaborado pelos autores (2021). 
Há uma ampla variedade de variáveis que são correlacionadas com a transparência. A ampla maioria das correlações correlacionou a transparência com variáveis sociais, econômicas e demográficas.

Já quanto a utilização de softwares, a Tabela 3 apresenta os mais utilizados:

Tabela 3 - Softwares utilizados

\begin{tabular}{l|c|c}
\multicolumn{1}{c|}{ Software estatístico utilizado } & Quantidade & $\%$ \\
\hline Statistical Package for the Social Sciences (SPSS) & 7 & 31,8 \\
\hline Microsoft Excel & 5 & 22,7 \\
\hline Stata & 2 & 9,1 \\
\hline$R$ & 1 & 4,5 \\
\hline Nenhum software informado & 9 & 40,9 \\
\hline
\end{tabular}

Fonte: elaborado pelos autores (2020).

Diante do observado, constata-se que os softwares mais utilizados para apoio e aplicação das técnicas estatísticas são o Microsoft Excel e o Statistical Package for the Social Sciences (SPSS). Verificou-se que tais softwares foram utilizados em $54,5 \%$ das publicações da amostra analisada. Em alguns estudos optou-se pela aplicação de mais de um software num mesmo artigo como Excel e Stata. Em contraponto em 40,9\% dos artigos não se evidenciou a utilização de nenhum software.

Buscou-se levantar a frequência existente das palavras-chaves contidas nos artigos analisados, conforme consta na Figura 1.

Figura 1 - Nuvem de palavras

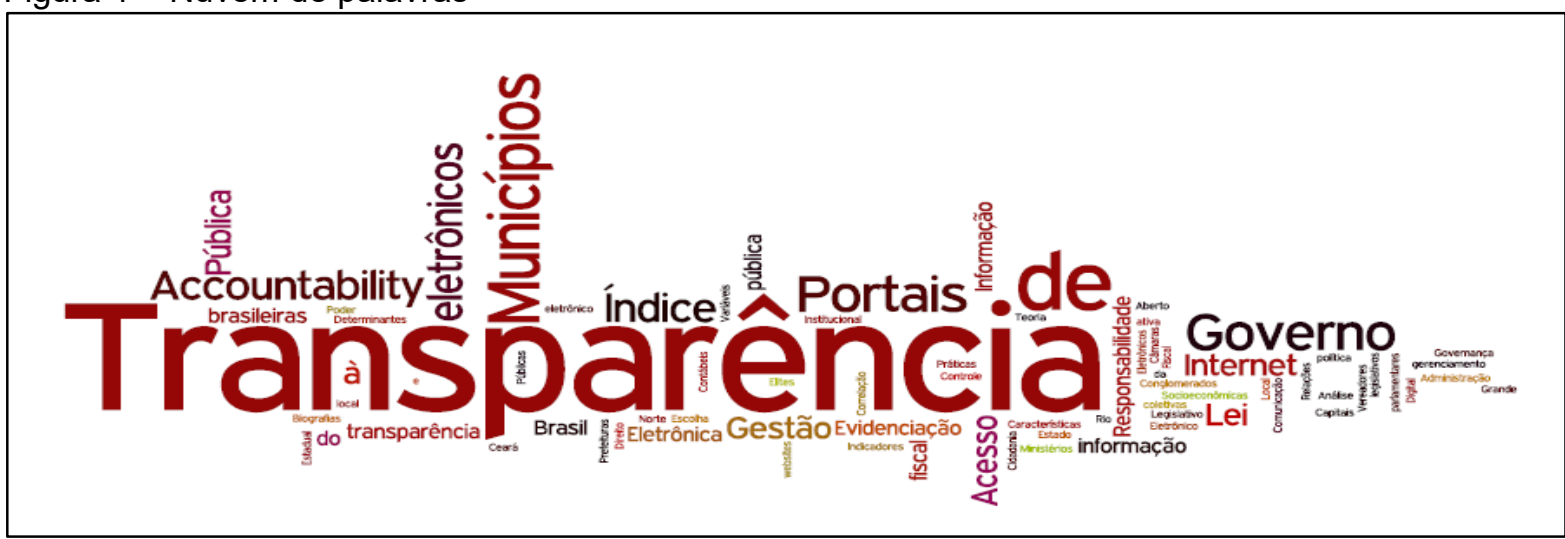

Fonte: elaborado pelos autores (2020).

Percebeu-se que no agrupamento e organização gráfica das palavras em função de sua frequência, as palavras mais evidenciadas foram: transparência, municípios, governo, portais, índice e accountability. Ramalho, Oliveira e Martins 
Utilização de métodos quantitativos em estudos de transparência em portais eletrônicos governamentais

(2019) enfatizam a importância da escolha das palavras-chaves na recuperação dos trabalhos acadêmicos indexados nas bases de dados por outros pesquisadores.

Com a finalidade de identificar a bibliografia de apoio utilizada em publicações com abordagem quantitativa sobre a presente temática, buscou-se analisar os autores citados nos artigos da amostra. Com isso, encontrou-se as referências abaixo como suporte nas análises estatísticas.

Quadro 3 - Bibliografia de suporte utilizada nos estudos da temática CUNHA, J. V. A.; COELHO, A. C. Regressão Linear Múltipla. In: CORRAR, L. J.; PAULO, E.; DIAS FILHO, J. M. (Coord.). Análise multivariada: para os cursos de administração, ciências contábeis e economia. São Paulo: Atlas, 2009, p. 131-231.

HAIR Jr., J. F. et al. Fundamentos de métodos de pesquisa em administração. Porto Alegre: Bookman, 2005.

TRIOLA, M. F. Introdução à estatística. 9 ed. Rio de Janeiro: LTC, 2005.

STEVENSON, W. J. Estatística Aplicada à Administração. São Paulo: Harbra, 1986.

FIELD, A. Descobrindo a estatística usando o SPSS. São Paulo: Bookman/Artmed. 2009.

CERVO, A. L.; BERVIAN, P. A.; SILVA, R. Metodologia científica. 6. ed. São Paulo: Prentice Hall, 2007.

MALHOTRA, N. K. Pesquisa de marketing: uma orientação aplicada. 6. ed. Porto Alegre: Bookman, 2006.

BORTOLUZZI, S. C.; ENSSLIN, S. R.; LYRIO, M. V. L.; ENSSLIN, L. Avaliação de desempenho econômico-financeiro: Uma proposta de integração de indicadores contábeis tradicionais por meio da Metodologia Multicritério de Apoio à Decisão Construtivista (MCDA-C). Revista Alcance, v. 18, n. 2, p. 200-218, 2011.

GUJARATI, D. N. Econometria básica. 4. ed. Rio de Janeiro: Elsevier, 2006.

HAIR Jr., J. F.; ANDERSON, R. E.; TATHAM, R. L.; BLACK, W. C.; BABIN, B.J. Análise Multivariada de Dados. 6. ed. Porto Alegre: Bookman, 2009.

HADI, A. S. Identificando vários outliers em dados multivariados. Jornal da Sociedade Estatística Real. Série B Metodológica, v. 54, n. 3, p. 761-771, 1992.

ENSSLIN, L.; MONTBELLER-NETO, G.; NORONHA, S. M. Apoio à decisão: metodologias para estruturação de problemas e avaliação multicritério de alternativas. Florianópolis: Insular, 2001.

MOORE, D. S. The Basic Practice of Statistics. New York: Freeman, 2007.

Fonte: elaborado pelos autores (2020).

Observou-se na bibliografia de suporte dos artigos da amostra a utilização de duas obras do professor Joseph Hair Jr., sendo uma que abrange a análise multivariada de dados e outra sobre métodos de pesquisa em administração. Bido e Silva (2019) sinalizam a importância das obras do professor Joseph Hair Jr. para a área de administração no Brasil, o qual é tido como referência em análises multivariadas. Diferentemente de mapeamentos metodológicos em outros temas, na presente pesquisa não houve recorrência do uso de bibliografias de suporte sendo que cada uma delas foi citada em um único artigo. Esta é uma característica de áreas incipientes da pesquisa científica visto que só em áreas mais maduras é possível haver uma recorrência no uso de bibliografias.

Ágora: R. Divulg. Cient., v. 27, p. 45-68, 2022 (ISSNe 2237-9010) 
De forma a apresentar os tamanhos e tipos de amostragem apresenta-se o Quadro 4.

Quadro 4 - Tamanho da amostra e tipo de processo de amostragem

\begin{tabular}{|c|c|c|}
\hline Autores & Descrição da amostra & Categoria \\
\hline Braga; Nicolás & $\begin{array}{l}1.059 \text { deputados legislativos em mandato } \\
\text { em } 2006,29 \text { legendas. }\end{array}$ & $\begin{array}{c}\text { Não-probabilística por } \\
\text { julgamento }\end{array}$ \\
\hline Cruz; Silva; Santos & $\begin{array}{l}23 \text { municípios do Estado do Rio de Janeiro } \\
\text { com população sup. a } 100.000 \text { habitantes }\end{array}$ & $\begin{array}{c}\text { Não-probabilística por } \\
\text { julgamento }\end{array}$ \\
\hline $\begin{array}{c}\text { Santana; Libonati; } \\
\text { Vasconcelos; Slomski }\end{array}$ & Toda população do estudo & Nenhuma técnica \\
\hline Keunecke; Teles; Flach & $\begin{array}{l}5 \text { (cinco) mais populosos municípios do } \\
\text { estados de Santa Catarina }\end{array}$ & $\begin{array}{c}\text { Não-probabilística por } \\
\text { julgamento }\end{array}$ \\
\hline $\begin{array}{l}\text { Cruz; Ferreira; Silva; } \\
\text { Macedo }\end{array}$ & $\begin{array}{l}100 \text { (cem) maiores municípios brasileiros, } \\
\text { com população, cerca de } 75,5 \text { milhões de } \\
\text { habitantes, mais de } 41 \% \text { do total da } \\
\text { população do país. }\end{array}$ & $\begin{array}{l}\text { Não-probabilística por } \\
\text { julgamento }\end{array}$ \\
\hline $\begin{array}{l}\text { Nunes; Santos; Farias; } \\
\text { Soares; Lunkes }\end{array}$ & $\begin{array}{l}51 \text { (cinqüenta um) municípios da região } \\
\text { Sul - com população de } 50.000 \text { a } 100.000 \\
\text { habitantes (IBGE). }\end{array}$ & $\begin{array}{l}\text { Não-probabilística pro } \\
\text { julgamento }\end{array}$ \\
\hline Souza;Barros;Araújo;Silva & $\begin{array}{l}8 \text { (oito) mais populosos municípios do RN, } \\
\text { mais } 50.000 \text { habitantes (IBGE 2010). }\end{array}$ & $\begin{array}{l}\text { Não-probabilística por } \\
\text { conveniência }\end{array}$ \\
\hline Rothberg; Liberato; & $\begin{array}{l}\text { Cidades-sede das } 15 \text { regiões } \\
\text { administrativas do Estado de São Paulo. }\end{array}$ & $\begin{array}{l}\text { Não-probabilística } \\
\text { conveniência }\end{array}$ \\
\hline Rodrigues; Salgueiro & $\begin{array}{l}\text { Avaliações realizadas pelo TCM-CE nos } \\
184 \text { municípios do estado do Ceará } \\
\text { durante o exercício de } 2014 .\end{array}$ & $\begin{array}{l}\text { Não-probabilística por } \\
\text { julgamento }\end{array}$ \\
\hline Raupp; Abreu; Abreu & $\begin{array}{l}133 \text { (cento trinta três) municípios } \\
\text { brasileiros com mais de } 200.000 \\
\text { habitantes }\end{array}$ & $\begin{array}{l}\text { Não-probabilística por } \\
\text { julgamento }\end{array}$ \\
\hline Diniz; Machado; Matos & $\begin{array}{l}157 \text { (cento cinqüenta sete) website dos } \\
\text { executivos municipais Cearenses ativos. }\end{array}$ & Não identificada \\
\hline $\begin{array}{l}\text { Campagnoni; Carvalho; } \\
\text { Lyrio; Lunkes; Rosa }\end{array}$ & $\begin{array}{l}24 \text { (vinte quatro) câmaras de vereadores } \\
\text { de capitais nacionais de municípios mais } \\
\text { populosos. }\end{array}$ & $\begin{array}{l}\text { Não-probabilística por } \\
\text { julgamento }\end{array}$ \\
\hline $\begin{array}{l}\text { Comin; Ramos; Zucchi; } \\
\text { Favretto; Fachi }\end{array}$ & $\begin{array}{l}121 \text { (cento vinte um) municípios }(41.02 \%) \\
\text { Santa Catarina, com mais } 10.000 \\
\text { habitantes (IBGE 2010) }\end{array}$ & $\begin{array}{l}\text { Não-probabilística por } \\
\text { acessibilidade }\end{array}$ \\
\hline Araújo; Romero & $\begin{array}{l}109 \text { maiores municípios espanhóis em } \\
2012 .\end{array}$ & $\begin{array}{c}\text { Não-probabilística por } \\
\text { julgamento }\end{array}$ \\
\hline Cole; Lyrio; Lunkes; Lima & Portais dos ministérios de Moçambique. & Nenhuma \\
\hline Salgado; Aires & $\begin{array}{l}46 \text { (quarenta seis) municípios do Rio } \\
\text { Grande de Norte que fazem parte Brasil } \\
\text { Transparente (BRASIL, 2015). }\end{array}$ & $\begin{array}{l}\text { Não-probabilística por } \\
\text { julgamento }\end{array}$ \\
\hline $\begin{array}{l}\text { Fiirst; Baldissera; Martins; } \\
\text { Nascimento }\end{array}$ & $\begin{array}{l}28 \text { unidades federativas, e um Distrito } \\
\text { Federal, dados de portais eletrônicos, } \\
\text { como os sites dos estados, o site da } \\
\text { Escala Brasil Transparente (EBT) }-2^{\mathrm{a}} \\
\text { edição. }\end{array}$ & $\begin{array}{l}\text { Não-probabilística por } \\
\text { julgamento }\end{array}$ \\
\hline $\begin{array}{l}\text { Michener; Contreras; } \\
\text { Niskier }\end{array}$ & $\begin{array}{l}\text { Banco de dados de } 3.550 \text { solicitações } \\
\text { compiladas de avaliações realizadas em } \\
\text { todo o país. }\end{array}$ & Não identificada \\
\hline Teixeira; Lamenha & 102 municípios do Estado de Alagoas. & Não identificada \\
\hline Dias; Garcia; & $\begin{array}{l}52 \text { (cinqüenta duas) cidades, capitais e } \\
\text { segunda maior cidade do Estado, } \\
\text { excetuando o Distrito Federal -DF }\end{array}$ & $\begin{array}{l}\text { Não-probabilística por } \\
\text { julgamento }\end{array}$ \\
\hline
\end{tabular}

Ágora: R. Divulg. Cient., v. 27, p. 45-68, 2022 (ISSNe 2237-9010) 


\begin{tabular}{|c|l|c|}
\hline Melo; Fuchigami & $\begin{array}{l}20 \quad \text { (vinte) melhores universidades } \\
\text { federais, segundo o IGC, do INEP. }\end{array}$ & $\begin{array}{c}\text { Não-probabilística por } \\
\text { julgamento }\end{array}$ \\
\hline Visentini; Santos & $\begin{array}{l}\text { Portais eletrônicos das 25 Prefeituras que } \\
\text { pertencem ao Corede Missões. }\end{array}$ & Não identificada \\
\hline
\end{tabular}

Fonte: elaborado pelos autores (2020).

Ficou evidente que em sua maioria as amostragens classificam-se como não probabilísticas por julgamento, o que para Fávero e Belfiore (2017) pode trazer elementos subjetivos na definição da amostra, e dificulta aferir a falha amostral. As amostras são predominantemente não probabilísticas porque dependem da disponibilidade dos dados e a disponibilidade dos dados é afetada por fatores que vão desde a disponibilidade de recursos (TI e pessoal) até a intenção dos dirigentes dos órgãos em ser mais ou menos transparentes. Vale lembrar que, a rigor, os achados derivados de pesquisas com amostragem não probabilística não podem ser generalizados para a população.

\section{CONSIDERAÇÕES FINAIS}

O objetivo da presente pesquisa foi delinear a utilização das abordagens quantitativas empregadas em pesquisas sobre a transparência em portais eletrônicos governamentais. Para atingir o objetivo da presente pesquisa, foi procedido um levantamento da aplicação de abordagens quantitativas em estudos voltados para a transparência em portais eletrônicos governamentais, a partir de busca nas bases de dados. Com isso, os principais resultados demonstram que:

i) as técnicas estatísticas utilizadas com maior frequência são as estatísticas descritivas (em 63,6\% na amostra analisada). No mais, foram evidenciadas também a utilização de outras técnicas estatísticas nas pesquisas como análise de regressão, análise de conglomerados e metodologia multicritério de apoio a decisão. No caso desta última técnica ocorreu sua utilização em uma forma adaptada, inclusive.

ii) percebeu-se que em $45,5 \%$ dos estudos foi utilizado a correlação de Pearson e a correlação de Spearman. Tais técnicas, embora muito úteis, também não podem ser consideradas sofisticadas, o que juntamente com o item do parágrafo acima corroboram as afirmações de Serra, Fiates e Martins (2014) acerca do uso de técnicas estatísticas simples por pesquisadores brasileiros na área de Administração. 
iii) a maioria dos estudos não utilizou nenhuma técnica de análise de confiabilidade, e o único caso que apresentou a informação sobre a confiabilidade usou o Alfa de Cronbach.

iv) o software Statistical Package for the Social Sciences (SPSS) foi o software mais utilizado como suporte na aplicação das técnicas estatísticas.

v) notou-se que a evidenciação de bibliografia de suporte foi bastante tímida e nenhuma das referências foi recorrente em mais de um artigo embora dois livros do mesmo autor tenham sido citados e o autor é ninguém menos que Joseph Hair Jr, o aclamado professor de marketing da Universidade do Sul do Alabama que em 2018 foi reconhecido pela Clarivate Analytics como componente do grupo de $1 \%$ de autores mais citados mundialmente na área de negócios e economia.

vi) constatou-se também a utilização de amostragem não-probabilísticas por julgamento na grande maioria das amostras.

Observou-se na presente pesquisa uma característica já recorrente na literatura que havia sido analisada que é a uma ausência de detalhamento dos procedimentos metodológicos. É importante frisar que o detalhamento insuficiente dos processos das pesquisas impede que as mesmas sejam replicadas, tanto para averiguação dos resultados, quanto para a construção de séries temporais de dados que permitiriam a identificação da evolução, ou não, da transparência ao longo do tempo.

Sugere-se para pesquisas futuras, analisar mais categorias de características de pesquisas quantitativas, como por exemplo, o atendimento as premissas das técnicas, e sugere-se ainda a consulta a outras bases de dados, para além da DOAJ, Redalyc e Scopus, que contemplem a literatura internacional como as bases Ebscohost, Emerald, Web of Science, Taylor \& Francis e Wiley. Em virtude da característica incipiente da temática, bases que contemplem teses e dissertações também podem ser consultadas em pesquisas futuras como a Proquest, Catálogo de Teses e Dissertações, da Capes e Biblioteca Digital de Teses e Dissertações da USP. 


\section{REFERÊNCIAS}

AGOSTI NETO, R. C. et al. Panorama do uso de métodos quantitativos em pesquisas sobre mensuração da capacidade absortiva. Capital Científico, v. 18, n. 4, p. 96-113, 2020.

ALMEIDA, J. E. F. Como aumentar a probabilidade de aprovação de artigos em periódicos? Análise dos pareceres de avaliadores da Revista Brasileira de Contabilidade. Revista Brasileira de Contabilidade, n. 206, p. 13-25, 2014.

ARAUJO, J. F. F. E.; TEJEDO-ROMERO, F. Local government transparency index: determinants of municipalities rankings. International Journal Of Public Sector Management, v. 29, n. 4, p. 327-347, 2016.

BAIRRAL, M. A. C.; SILVA, A. H. C.; ALVES, F. J. S. Transparência no setor público: uma análise dos relatórios de gestão anuais de entidades públicas federais no ano de 2010. Revista de Administração Pública, v. 49, n. 3, p. 642-675, 2015.

BIDO, D. S.; MANTOVANI, D. M. N.; COHEN, E. D. Destruição de escalas de mensuração por meio da análise fatorial exploratória nas pesquisas da área de produção e operações. Gestão \& Produção, v. 25, n. 2, p. 384-397, 2018.

BIDO, D. S.; SILVA, D. Importance of Hair's Books in Brazilian Business Research. In: The Great Facilitator. Springer, Cham, 2019. p. 167-173. In: BARRY, J. B.; SARSTEDT, M. (Org.). The great facilitator. 1.ed. Switzerland: Springer, Cham., 2019, v. 1, p. 167-173.

BORGES, G. J. R. et al. Panorama do uso de métodos quantitativos em pesquisas sobre marketing de relacionamento com egressos. Revista de Administração, Sociedade e Inovação, v. 6, n. 3, p. 78-97, 2020.

BRAGA, S. S.; NICOLÁS, M. A. Prosopografia a partir da web: avaliando e mensurando as fontes para o estudo das elites parlamentares brasileiras na internet. Revista de Sociologia e Política, v. 16, n. 30, p. 107-130, 2008.

CAMPAGNONI, M. et al. Transparência no poder legislativo municipal: uma análise dos portais eletrônicos das câmaras de vereadores das capitais brasileiras. Revista gestão organizacional, v. 9, n. 1, p. 21-42, 2016.

CASTRO, C. M. A prática da pesquisa. 2. ed. São Paulo: Pearson Prentice Hall, 2006.

COLE, B. P. et al. Transparência Pública Mediada por Computadores: como estão os ministérios de Moçambique à luz da legislação? Cadernos de Estudos Africanos, n. 34, p. 197-227, 2017.

COMIN, D. et al. Transparência Ativa nos Municípios de Santa Catarina: avaliação do índice de atendimento à lei de acesso à informação e suas determinantes.

Revista Catarinense da Ciência Contábil, v. 15, n. 46, p. 24-34, 2016. 
COOPER, Donald R.; SCHINDLER, Pamela S. Métodos de pesquisa em administração. 12. ed. Porto Alegre: AMGH, 2016.

CRUZ, C. F. et al. Transparência da gestão pública municipal: um estudo a partir dos portais eletrônicos dos maiores municípios brasileiros. Revista Administração

Pública, v. 46, n. 1, p. 153-176, 2012.

CRUZ, C. F.; SILVA, L. M.; SANTOS, R. Transparência da gestão fiscal: um estudo a partir dos portais eletrônicos dos maiores municípios do Estado do Rio de Janeiro. Revista Contabilidade, Gestão e Governança, v. 12, n. 3, p. 102-115, 2009.

DALLABONA, L. F.; NASCIMENTO, S.; HEIN, N. Métodos estatísticos mais recorrentes nas dissertações do programa de pós-graduação em Ciências Contábeis da FURB. Revista de Contabilidade da UFBA, v. 4, n. 1, p. 56-70, 2010.

DALLABONA, L. F.; RODRIGUES JR., M. M.; HEIN, N. Métodos estatísticos: Análise dos estudos publicados nos anais de congressos da ANPAD. In: SEMINÁRIOS EM ADMINISTRAÇÃO, 14., 2011, São Paulo. Anais [...]. São Paulo: USP, 2011.

DAMÁZIO, D. R.; SOARES, S. V; LIMA, C. R. M. O uso de métodos quantitativos em pesquisas sobre avaliação da implementação de sistemas de informação em saúde. Revista de Gestão e Secretariado, v. 11, n. 3, p. 109-132, 2020.

DIAS, T.; GARCIA, A. B.; CAMILO, N. Um olhar sobre o governo aberto no nível subnacional. GIGAPP Studies Working Papers, v. 6, n. 111-115, p. 83-100, 2019.

DINIZ, G. M.; MACHADO, D. Q.; MATOS, F. R. N. Transparência Digital na Gestão Pública: uma análise de conglomerados nos municípios cearenses. Revista

Controle - Doutrina e Artigos, v. 14, n. 2, p. 197-217, 2016.

ESPEJO, M. M. S. B. et al. O mercado acadêmico contábil brasileiro: uma análise do cenário a partir das práticas de publicação e avaliação por pares. Revista Universo Contábil, v. 9, n. 4, p. 6-28, 2013.

FALASTER, C.; FERREIRA, M. P.; CANELA, R. Motivos de rejeição dos artigos nos periódicos de administração. Organizações e Sociedade, v. 23, n. 77, p. 285-306, 2016.

FÁVERO, L. P. L. et al. Análise de dados: modelagem multivariada para tomada de decisões. Rio de Janeiro: Elsevier, 2009.

FÁVERO, L. P.; BELFIORE, P. Manual de análise de dados: estatística e modelagem multivariada com Excel, SPSS e Stata. Rio de Janeiro: Elsevier, 2017.

FERREIRA, M. P.; FALASTER, C. Uma Análise Comparativa dos Fatores de Rejeição nos Periódicos de Diferentes Estratos de Administração. Revista de administração contemporânea, v. 20, n. 4, p. 412-433, 2016. 
FIATES, G. G. S.; SERRA, F. A. R.; MARTINS, C. A aptidão dos pesquisadores brasileiros pertencentes aos programas de pós-graduação stricto sensu em Administração para pesquisas quantitativas. Revista Administração, v. 49, n. 2, p. 384-398, 2014.

FIIRST, C. et al. A influência dos índices socioeconômicos e contábeis no nível de transparência eletrônica dos estados brasileiros sob a ótica da teoria da escolha pública. Revista Administração Pública e Gestão Social, v. 10, n. 4, p. 272-281, 2018.

GALVÃO, N.; SILVA, L. V. B.; MERCÊS, R. K. M. Fatores de rejeição de artigos em periódicos de Ciências Contábeis. Revista Gestão e Organizações, v. 2, n. 2, p. 122, 2018.

GOUVÊA, M. A.; PREARO, L. C.; ROMEIRO, M. C. Abordagem exploratória do emprego das técnicas de análise de regressão e análise conjunta em estudos comportamento do consumidor. Revista Brasileira de Gestão de Negócios, v. 12, n. 36, p. 253-270, 2010.

GOUVÊA, M. A.; PREARO, L. C.; ROMEIRO, M. C. Avaliação do emprego da técnica de análise multivariada de variância em teses e dissertações de algumas instituições de ensino superior. Revista Estudos do CEPE, v. 34, p. 69-97, 2011.

HOSSER, C.; CRUZ, A. P. C.; QUINTANA, A. C. Mapeamento dos Métodos Quantitativos Utilizados no Congresso Anpcont (2007-2015). Revista de Contabilidade da UFBA, v. 12, n. 3, p. 153-174, 2018.

KEUNECKE, L. P.; TELES, J.; FLACH, L. Práticas de Accountability: uma análise do índice de transparência nos municípios mais populosos de Santa Catarina. Revista Contemporânea de Contabilidade, v. 8, n. 16, p. 153-174, 2011.

LANA, J. et al. Caso para Ensino: O processo de escolhas metodológicas em uma Abordagem Quantitativa. Revista de Contabilidade e Organizações, v. 12, n. 1, p. 1-11, 2018.

LATTIN, J.; CARROLL, J. D.; GREEN, P. E. Análise de dados multivariados. São Paulo: Cengage Learning, 2011.

MARTINS, G. A. Avaliação das avaliações de textos científicos sobre contabilidade e controladoria. Revista de Educação e Pesquisa em Contabilidade, v. 1, n. 1, p. 113, 2007.

MELO, D. A.; FUCHIGAMI, H. Y. Proposta de índice bidimensional de transparência da informação público-eletrônica como ferramenta para participação e controle sociais. Read. Revista Eletrônica de Administração, v. 25, n. 2, p. 179-214, 2019.

MICHENER, G.; CONTRERAS, E.; NISKIER, I. Da opacidade à transparência? Avaliando a Lei de Acesso à Informação no Brasil cinco anos depois. Revista de Administração Pública, v. 52, n. 4, p. 610-629, 2018. 
MORAIS, M. G. M.; GUERRA, L. C. B. Lei de acesso à informação: uma análise dos portais e sítios eletrônicos oficiais das prefeituras do RN. EmpíricaBR - Revista Brasileira de Gestão, Negócio e Tecnologia da Informação, v. 1, n. 2, p. 85-104, 2016.

NUNES, G. S. F. et al. Análise dos instrumentos de Transparência contidos na lei de responsabilidade fiscal nos municípios da região sul. Revista Ambiente Contábil, v. 5. n. 2, p. 128-150, jul./dez. 2013.

PREARO, L. C.; GOUVÊA, M. A.; MONARI, C. Avaliação do emprego da técnica de análise de regressão logística em teses e dissertações de algumas instituições de ensino superior. Semina. Ciências Sociais e Humanas (Online), v. 30, n. 2, p. 3754, 2009.

PREARO, L. C.; GOUVÊA, M. A.; ROMEIRO, M. C. Avaliação da adequação de aplicação de técnicas multivariadas de dependência em teses e dissertações de algumas instituições de ensino superior. Ensaios FEE (Online), v. 33, n. 1, p. 261290, 2012.

PREARO, L. C.; GOUVÊA, M. A.; ROMEIRO, M. C. Avaliação do emprego das técnicas de análise de regressão e correlação canônica em teses e dissertações de algumas instituições de ensino superior. Revista Ciências Administrativas, v. 17, n. 3, p. 691-727, 2011a.

PREARO, L. C.; GOUVÊA, M. A.; ROMEIRO, M. C. Avaliação do emprego da técnica de modelagem de equações estruturais em teses e dissertações de universidades públicas de alta performance. Revista da FAE, v. 14, n. 2, p. 80-99, 2011b.

RAMALHO, C.; OLIVEIRA, J.; MARTINS, P. Análise bibliométrica das publicações do programa de Ciência, Tecnologia e Sociedade da Universidade Federal de São Carlos. Rdbci: Revista Digital de Biblioteconomia e Ciência da Informação, v. 17, p. 1-16, 2019.

RAUPP, F.M.; ABREU, E.; ABREU, M. B. Disponibilização de Informações à Sociedade em Meios Eletrônicos: um estudo nas prefeituras dos maiores municípios brasileiros. Revista Catarinense da Ciência Contábil, v. 14, n. 42, p. 41-54, 2015.

RODRIGUES JÚNIOR, M. S.; SALGUEIRO, V. A. G. Transparência na Gestão Fiscal nos Municípios do Estado do Ceará. Revista Controle - Doutrina e Artigos, v. 13, n. 1, p. 47-63, 2015.

ROTHBERG, D.; LIBERATO, F. P. Comunicação pública, transparência e políticas públicas: avaliação de informações em portais brasileiros de governo. Revista Internacional de Relaciones Públicas, v. 3, n. 6, p. 69-96, 2013.

SALGADO, C. C. R.; AIRES, R. F. F. Governo eletrônico no Rio Grande do Norte: uma avaliação de prefeituras municipais a partir de lei de acesso à informação.

Perspectivas em Ciência da Informação, v. 22, n. 3, p. 98-115, 2017. 
SANTANA JUNIOR, J. J. B. et al. Transparência fiscal eletrônica: uma análise dos níveis de transparência apresentados nos sites dos poderes e órgãos dos estados e do distrito federal do Brasil. Revista de Educação e Pesquisa em Contabilidade REPeC, v. 3, n. 3, p. 62-84, 2009.

SOARES, S. V.; PICOLLI, I. R. A.; CASAGRANDE, J. L. Pesquisa Bibliográfica, Pesquisa Bibliométrica, Artigo de Revisão e Ensaio Teórico em Administração e Contabilidade. Administração: Ensino e Pesquisa, v. 19, n. 2, p. 308-339, 2018.

SOARES, T. C.; SOARES, J. C.; SOARES, S. V. Pesquisa quantitativa em turismo: os dados gerados são válidos e confiáveis? Revista Iberoamericana de Turismo (Ritur), n. 9, p. 162-174, 2019.

SOUZA, F. J. V. et al. da. Índice de transparência municipal: um estudo nos municípios mais populosos do Rio Grande do Norte. Revista de Gestão, Finanças e Contabilidade, v. 3, n. 3, p. 94-113, 2013.

TEIXEIRA, J. V.; LAMENHA, A. Â. R. Transparência e índices de gestão em entidades públicas como ferramenta de controle e desempenho: uma comparação entre indicadores municipais de Alagoas - Brasil. Revista Científica Visão Futura, v. 23, n. 1, 2019.

VISENTINI, M. S.; SANTOS, M. Transparência na Gestão Pública Municipal Evidenciada nos Portais Eletrônicos dos Municípios do Conselho Regional de Desenvolvimento (Corede) das Missões/RS. Desenvolvimento em Questão, v. 17, n. 49, p. 158-175, 2019.

Artigo recebido em: 14/05/2021

Artigo aprovado em: 02/12/2021

Artigo publicado em: 16/02/2022 